удК $339.97(47+57)$

\title{
МАКРО- И МЕТАЭКОНОМИЧЕСКИЕ ТЕНДЕНЦИИ В РАЗВИТИИ ЛОГИСТИЧЕСКОЙ ИНФРАСТРУКТУРЫ
}

\author{
П.А. ЛАВРЕНТЬЕВ \\ ассистент кафедры экономики и управления \\ Белорусский государственный экономический университет, г. Минск
}

\section{Аннотация}

В статье дается оценка состояния логистической системы и ее значимости для мировой экономики. Проводиться анализ логистической среды Республики Беларусь в разрезе мировых контейнерных перевозок с точки зрения формирования начиональной логистической инфраструктуры, а так же влияния состояния инфраструктурь на внутренний и транзитный товарньій поток, проходящий по территории Беларуси.

\section{Abstract}

The article assesses the state of the logistics system and its significance for the global economy. Examine national logistic Protection of the Republic of Belarus in the context of the world's container traffic from the point of view of the formation of logistics infrastructure, as well as the impact of the infrastructure on the domestic and the transit flow of goods passing through the territory of Belarus.

\section{ВВЕДЕНИЕ}

Национальная экономическая система современного государства использует совокупный мировой производственный потенциал и интегрирована в единый глобальный комплекс социально-экономических отношений. Подобный уровень взаимозависимости подразумевает развитие подхода к организации национальных материальных потоков с точки зрения не только полного учета физического перемещения товаров и ресурсов, но и формирования и развития совокупной системы логистических отношений.

С экономической точки зрения логистическая система - это система, элементами которой являются материальные, финансовые и информационные потоки, которые направляются логистическими операциями, взаимосвязывающими эти элементы в соответствии с общими целями и критериями эффективности [1].

С помощью элементов логистики решается основная экономическая проблема обеспечения взаимосвязи хозяйствующих субъектов и распределения ресурсов между ними. Кроме этого, удельная стоимость логистических операций в цене конечного продукта, а так же ее значимость в формировании экономических связей ставит логистику в ряд основных влияющих структур социально-экономических отношений.

\section{РЕЗУЛЬТАТЫ И ИХ ОБСУЖДЕНИЕ}

По данным Всемирного банка, логистические расходы составляют от 15 до 30 \% ВВП и от 20 до 60 \% конечной цены такой категории товаров, как продукты питания.

В свою очередь, Межамериканский банк развития (IDB) оценивает транспортную составляющую как образующую до двух третей общей стоимости всех логистических операций, то есть порядка 15 \% конечной цены товаров. Это объясняет значительные государственные расходы некоторых стран на транспортно-логистическую отрасль (до $50 \%$ бюджета).

Удельный вес мирового внешнеторгового оборота в мировом ВВП увеличился с 39 \% в 1990 г. до 59 \% в 2011 г. Современный внешнеторговый оборот превышает 20 трлн долл. США. Такое резкое увеличение объемов международной торговли за последние 20 лет в значительной мере обусловлено изменениями в политике логистических отношений и институциональной среды, приведшими к сокращению операционных затрат в узлах логистических сетей и пограничных барьеров. Согласно генеральному отчету Всемирного экономического форума в Давосе, состоявшегося в 2013 г., снижение таможенных и системных (институциональных) барьеров во всех странах позволит увеличить мировой ВВП на 2,6 \%, а в случае повышения уровня использования современных технологий в логистической отрасли на $50 \%$, мировой ВВП увеличится на 4,7 \% [2].

За последние 30 лет государства снизили таможенные пошлины в среднем на 5-10 \%, что обеспечило не только либерализацию торговли, но и технологические и организационные изменения в глобальной торговле. Параллельно происходит снижение нетарифных барьеров, которые имеют серьезное влияние на конечную цену товара.

Вышеперечисленные факты подтверждают зависимость мировой экономики от эффективной эксплуатации объектов логистической инфраструктуры. Таким образом, качественное использование инфраструктуры национальной экономики в рамках планирования, эксплуатации, обновления основных фондов в соответствии с социальноэкономическими требованиями и потребностями мирового воспроизводства дает странам значительное преимущество в мировом экономическом сообществе.

В мировой практике существует несколько методов оценки логистического потенциала национальной экономики. Каждый из них имеет собственную специализацию. 
Первым методом является определение индекса логистической эффективности (LPI). Данный индекс позволяет проследить тенденции развития отдельных логистических видов деятельности по странам мира.

Таблица 1 - Рейтинг LPI стран — членов СНГ [3,4,5,6]

\begin{tabular}{|l|c|c|c|c|}
\hline \multirow{2}{*}{\multicolumn{1}{c|}{ Страна }} & \multicolumn{4}{|c|}{ Итоговый рейтинг LPI } \\
\cline { 2 - 5 } & 2007 г. & 2010 г. & 2012 г. & 2014 г. \\
\hline Латвия* & 58 & 37 & 76 & 36 \\
\hline Эстония & 42 & 43 & 65 & 39 \\
\hline Литва* & 52 & 45 & 58 & 46 \\
\hline Украина* & 97 & 102 & 66 & 61 \\
\hline Казахстан & 139 & 62 & 86 & 88 \\
\hline Россия* & 137 & 94 & 95 & 90 \\
\hline Армения & 118 & 111 & 100 & 92 \\
\hline Молдова & 110 & 104 & 132 & 94 \\
\hline Беларусь & $\mathbf{5 0}$ & & $\mathbf{9 1}$ & $\mathbf{9 9}$ \\
\hline Таджикистан & 140 & 131 & 136 & 114 \\
\hline Грузия & & 93 & 77 & 116 \\
\hline Азербайджан & 95 & 89 & 116 & 125 \\
\hline Узбекистан & 136 & 68 & 117 & 129 \\
\hline Туркменистан & & 114 & & 140 \\
\hline Киргизия & 102 & 91 & 130 & 149 \\
\hline
\end{tabular}

Примечание - Знаком «*» обозначены страны СНГ, граничащие с Беларусью.

LPI позволяет дать характеристику отдельных видов логистической деятельности, оценивая их в рамках разработанной методики (исходя из полученных ретроспективных данных), но не раскрывает потенциал страны как части глобальной логистической системы. Подобное ограничение распространяется и на оцениваемые виды логистической деятельности.

Несмотря на ограниченность выводов, опирающихся на обобщенные данные LPI, показатели позволяют оценить положение страны в системе, состоящей из государств с высокой степенью схожести в сфере логистики. Выделенная группа из 15 стран — бывших членов СНГ (таблица 1) имеет достаточно много общего для системного анализа. В частности, это:

- единая база управления производственным комплексом до 1990 г.;

- централизованное управление логистической системой до 1990 г;

- адаптированная под общие требования экономики СССР логистическая инфраструктура;

- единый размер железнодорожной колеи;

- отсутствие языкового барьера.

В соответствии с LPI рейтинг Республики Беларусь за последние семь лет значительно снизился (с 50-го места до 99-го). Подобное снижение произошло в период активизации развития транспортно-логистической деятельности в Беларуси, в процессе которого был разработан и утвержден ряд документов: Программа развития логистической системы Республики Беларусь на период до 2015 года (утверждена постановлением Совета Министров Республики Беларусь от 29.08.2008 № 1249), Модельный закон СНГ «О транспортной деятельности», Программа развития транзитного потенциала Республики Беларусь на 2011-2015 годы, программа «Дороги Беларуси» на 2006-2015 гг., ряд других подзаконных актов, в которых определены мероприятия, направленные на создание условий по развитию транспортно-логистической деятельности.

Программой развития логистической системы Республики Беларусь на период до 2015 года предусмотрено строительство логистических центров на 36 участках (первоначально предполагалось строительство 50 логистических центров). В реализацию программы вложено 3,146 трлн. руб., в том числе 75 \% этой суммы инвестировано в Минской области. Здесь же расположены 11 из 15 действующих логистических центров.

Сравнительный анализ значений показателей, входящих в LPI, для Беларуси, а также их мест в мировом рейтинге позволяет выявить причины снижения общего рейтинга страны. Значительное уменьшение мест в рейтинге за 2014 г. по всем показателям, кроме инфраструктуры, говорит о меньшем отставании Беларуси по параметрической шкале, чем по оценочной. Подобная тенденция обусловлена тем, увеличение параметрических показателей остальных стран было значительно большим, чем уменьшение показателей Беларуси.

Несмотря на проводимые мероприятия, оценка независимых компаний - участников логистической деятельности в период с 2007 по 2014 г. снижалась, что говорит о недостаточности действий по улучшению отдельных сегментов логистики и зависимости мнения потенциальных инвесторов о привлекательности национальной логистической среды от качества всей системы в целом. Кроме увеличения качественных и количественных показателей основных 
объектов логистики требуется внедрение системного подхода к оптимизации логистической среды национальной экономики (рисунок 1).

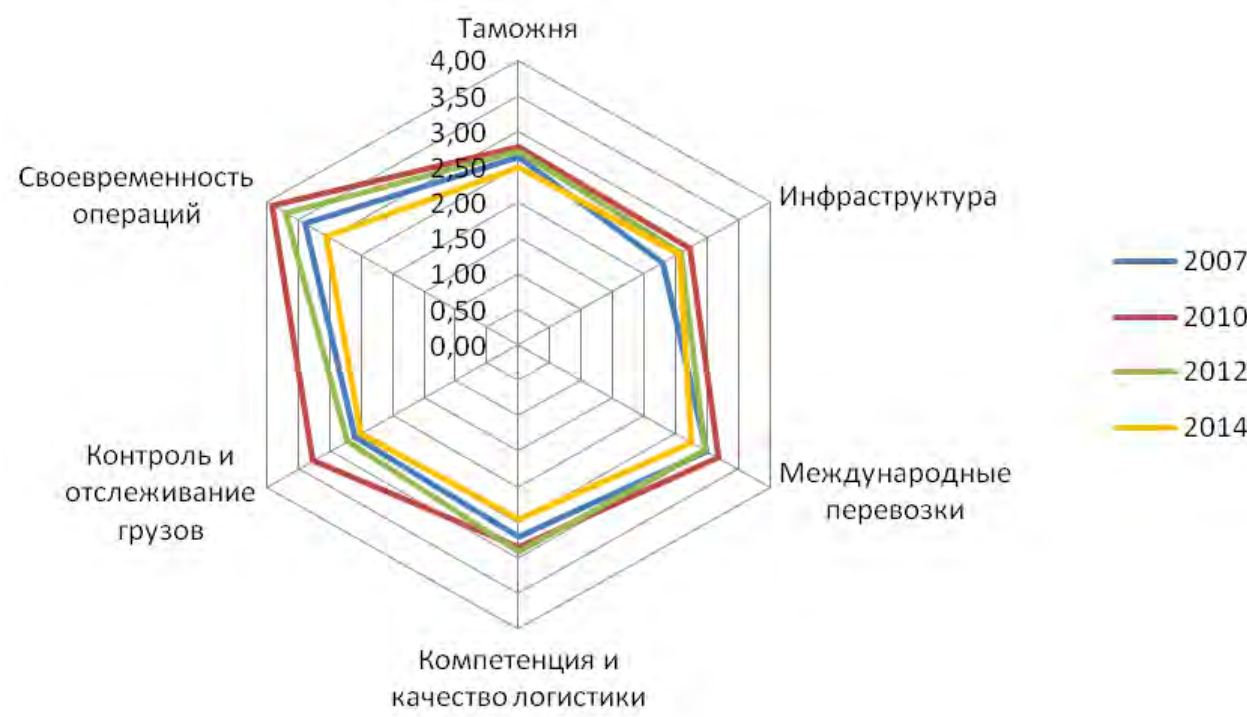

a)

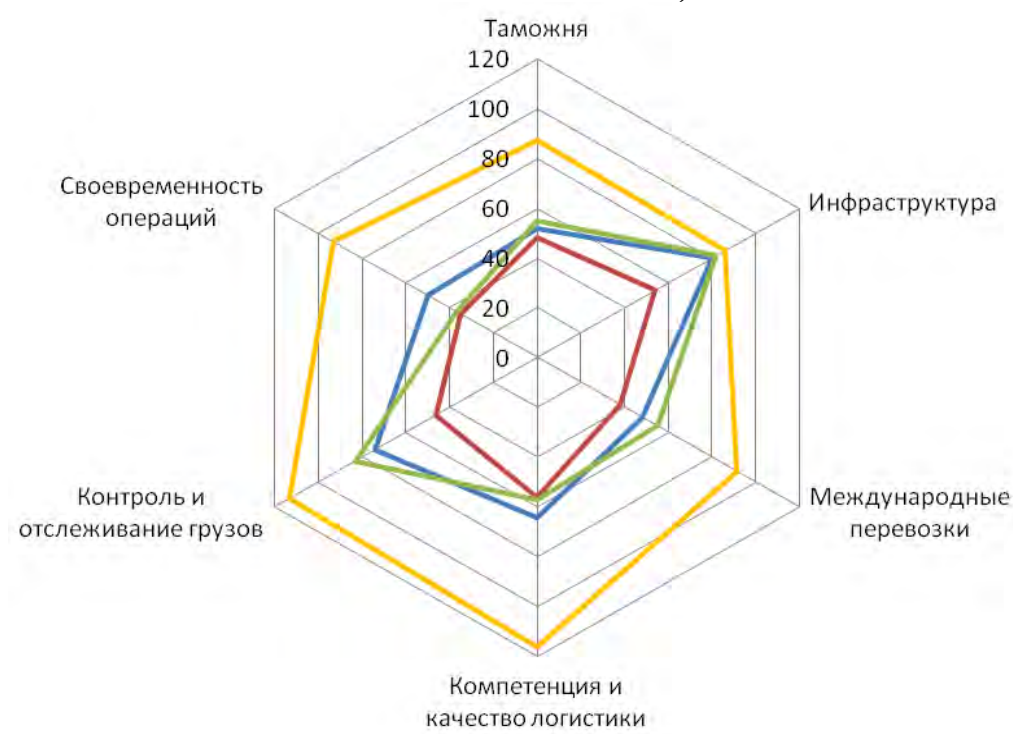

б)

Рисунок 1 - Показатели, входящие в LPI, для Беларуси за 2007-2014 гг.: а) значения (параметрическая шкала); б) место в мировом рейтинге (оценочная шкала)

Примечание - Собственная разработка

Группой исследователей Белорусского государственного экономического университета под руководством профессора И.И. Полещук был произведен сравнительный анализ уровня развития логистики в странах СНГ, Литве, Латвии, Эстонии, Грузии [3-А].

Исследуемые страны были разделены на три труппы:

1.Эстония, Литва, Латвия, Украина.

2.Казахстан, Российская Федерация, Армения, Молдова и Республика Беларусь.

3. Таджикистан, Грузия, Азербайджан, Узбекистан, Туркменистан, Киргизия.

По итогам анализа логистических услуг в странах второй группы, которая включает в себя Республику Беларусь, было выявлено, что в 2013 г. Казахстан занимал лидирующие позиции по показателю «своевременность доставки», Россия - по показателям «уровень инфраструктуры» и «спутниковое сопровождение», Армения — по показателям «таможенный сервис» и «логистический сервис», Молдова - по показателю «международные перевозки». В 2011-2012 гг. Казахстан также занимал первое место в данной группе, лидируя по показателям «таможенный сервис», «международные перевозки», «логистический сервис» и «спутниковое сопровождение». Лидером по уровню инфраструктуры в данный период являлась Республика Беларусь, по своевременности доставки - Армения. По последнему показателю Республика Беларусь обгоняла Казахстан. 
По данным SWOT-анализа были рассчитаны индексы возможностей и преимуществ. На основе данных индексов была построена матрица состояния логистической сферы стран СНГ, Литвы, Латвии, Эстонии, Грузии (рисунок 4).

По итогам SWOT-анализа можно сделать вывод о том, что по уровню развития транспортно-логистической сферы анализируемые страны делятся на три группы:

1)страны, в которых возможности превышают угрозы, сильных сторон больше, чем слабых (Россия, Беларусь, Украина, Казахстан, Литва, Латвия, Эстония);

2)страны, в которых возможности превышают угрозы, однако слабых сторон больше, чем сильных (Молдова, Армения, Азербайджан, Грузия Киргизия);

3)страны, в которых угрозы превышают возможности, слабых сторон больше, чем сильных (Узбекистан, Таджикистан, Туркменистан).

На основе проведенного анализа логистической сферы стран СНГ, Литвы, Латвии, Эстонии, Грузии можно сделать вывод о том, что логистика в них развивается различными темпами, в разных векторах и для них характерно отсутствие четко выраженных тенденций. Несмотря на нестабильную среду, которая предполагает низкий уровень развития логистики, присутствуют основные приоритеты развития, основанные на географическом и геополитическом положении стран-участников.

Следует выделить три основных направления, по которым осуществляется интеграция белорусской логистической системы в экономическое пространство СНГ:

1)Россия (кроме направлений, включенных в группы 2 и 3), Казахстан, Узбекистан, Киргизия, Туркменистан, Таджикистан;

2)Балтийский регион (Литва, Латвия, Эстония, Северо-Западный федеральный округ России);

3)Каспийско-Черноморский регион (Украина, Армения, Грузия, Азербайджан, Северо-Кавказский федеральный округ России, Крым).

Еще одно перспективное направление, которое следует учесть с точки зрения национальной логистической деятельности, это поток, организованный на основании производственно-экономических отношений Беларуси со странами Европейского Союза.

Кроме этих направлений через Республику Беларусь проходят транзитные потоки, которые не имеют отношения к прямому воспроизводству белорусской национальной экономики, однако существует их вовлеченность в экономическую систему страны. Это потоки, соединяющие крупнейшие Европейские и Азиатские экономические регионы.

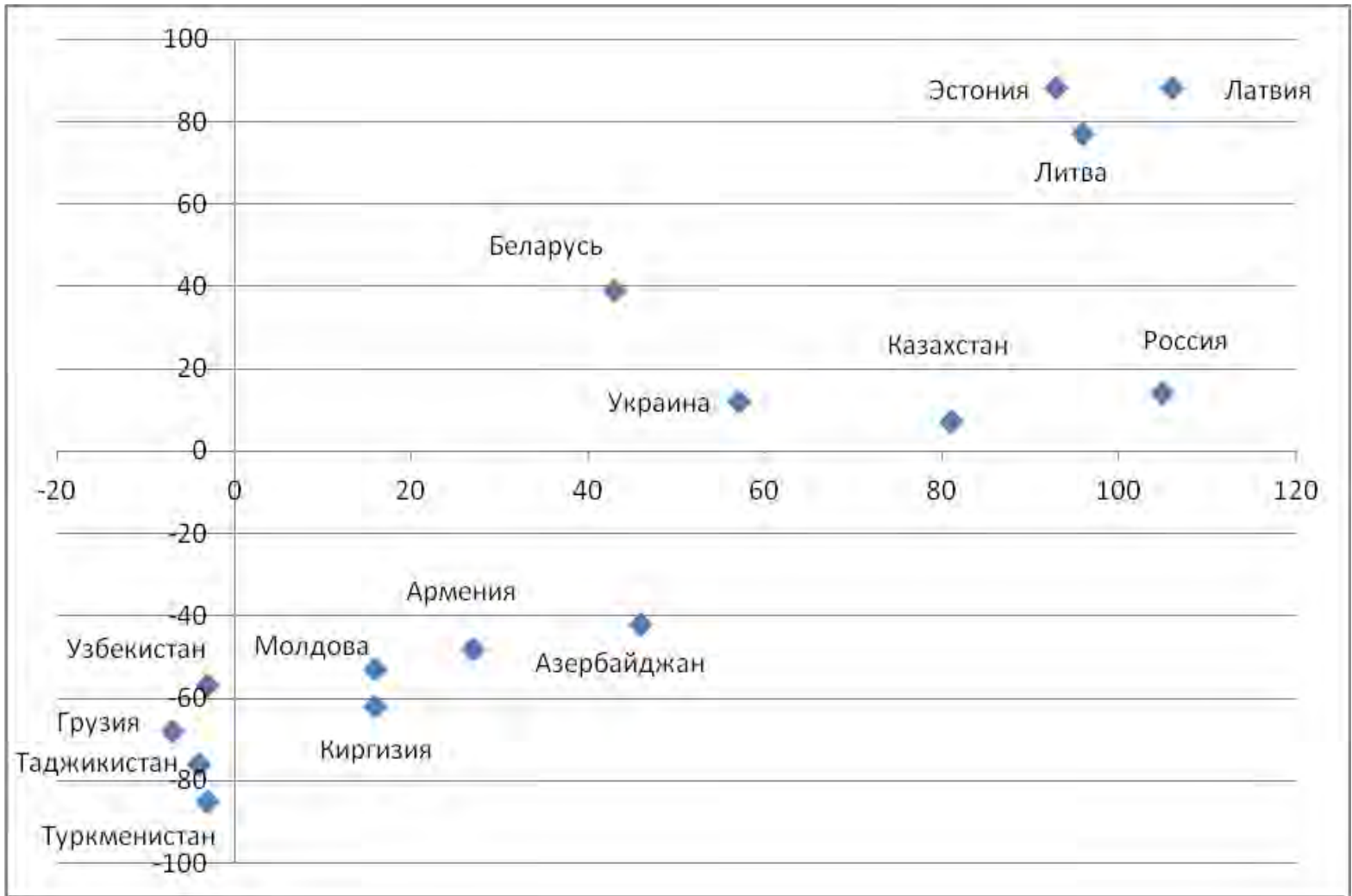

Рисунок 2 - Матрица состояния транспортно-логистической сферы стран СНГ, Литвы, Латвии, Эстонии, Грузии [7]

Структура логистической системы Беларуси включает в себя все виды деятельности, традиционно присутствующие на глобальном рынке логистических услуг. Так как логистика напрямую связана с управлением пространственно-временными перемещениями материальных потоков, то транспортная услуга является базисной операцией в логистической деятельности. В качестве одной из определяющих структур логистических потоков можно выделить наиболее распространенный тип доставки: контейнерные перевозки. 
Если рассматривать глобальный товаропоток с включением межконтинентальных перевозок по морю, то контейнерные перевозки занимают 50-60\% от общего числа морских перевозок (рисунок 3). Доля перевозок в контейнерах генеральных грузов (т.е. штучных грузов, перевозимых в упаковке) составляет более 90 \%. Среднегодовой прирост контейнерных перевозок равен 9 \% (за исключением 2012-13 года).

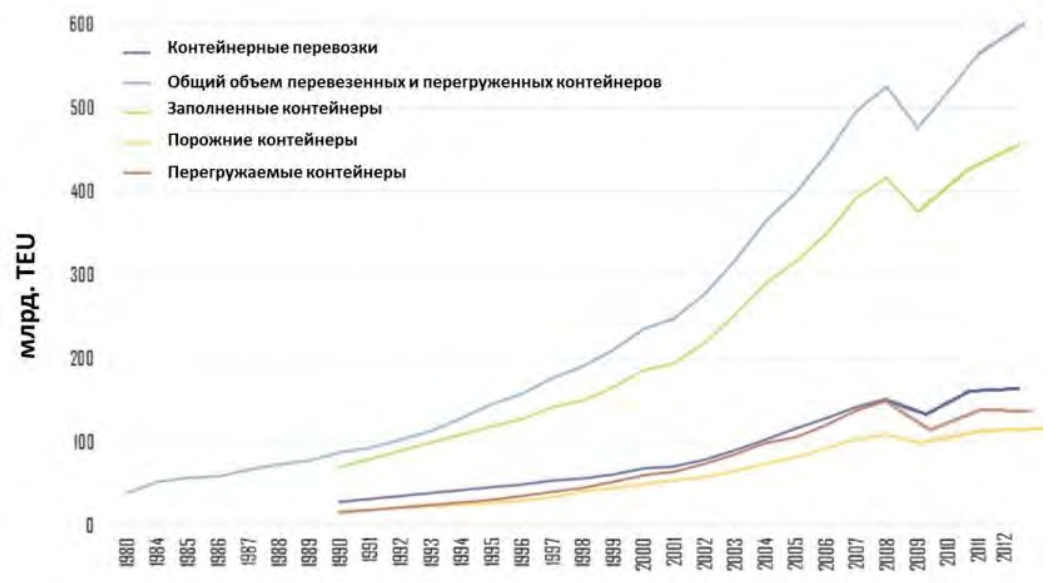

Рисунок 3 - Прирост контейнерных перевозок в TEU (Twenty-FootEquivalentUnit — эквивалент 20-футового контейнера) [8]

После экономического кризиса рынок контейнерных перевозок восстанавливается за счет увеличения мирового внешнеторгового оборота. При этом кризис еврозоны имеет наибольшую инерцию, что отразилось на контейнерных перевозках по основным портам. В 2012 г. порт Гамбург снизил перевалку контейнеров на 1,7 \%. Снижение роста контейнеро-оборота в балтийских портах с 23 \% в 2011 г. до $13 \%$ в 2012 г., по оценкам экспертов, произошло за счет их слабой территориальной привлекательности [9].

Основной мировой рост контейнерных перевозок после кризиса произошел на рынках Азии, Африки и Северной Америки (рисунок 4).

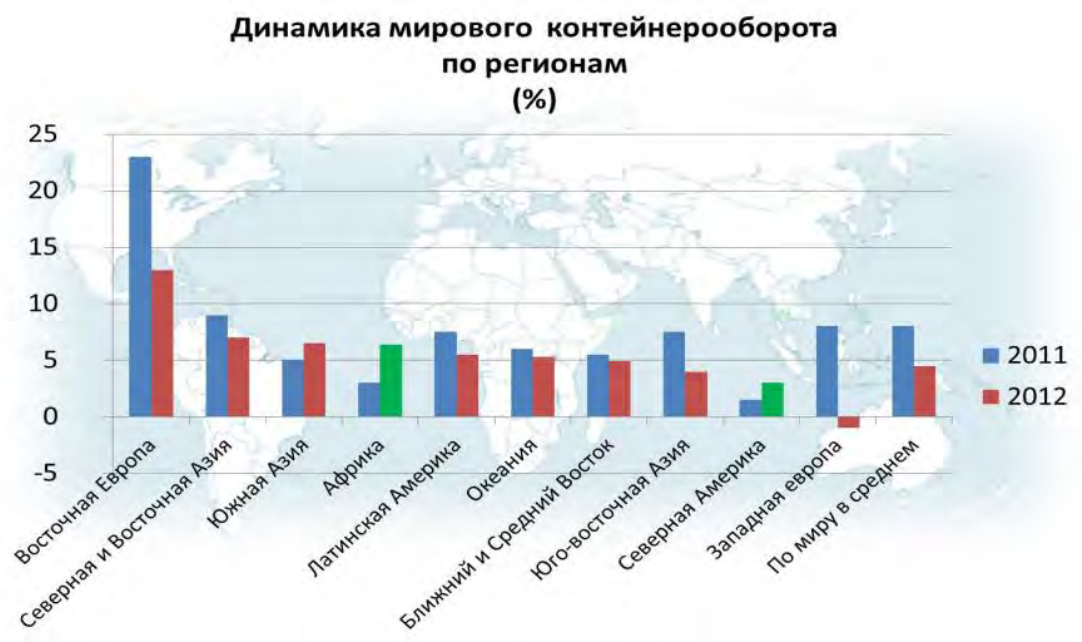

Рисунок 4 - Сравнительный анализ контейнеро-оборота в 2011-2012 гг. [10]

Рассмотрение темпов роста контейнерных перевозок в период с 2007 по 2012 г. позволяет сделать вывод о том, что значительное увеличение объемов контейнерных перевозок в 2010 г. обусловлено послекризисной компенсацией потребностей рынка. В последующие годы мировой внешнеторговый оборот стабилизировался: в 2013 г., по данным агентства DrewryShippingConsultantsLimited (рисунок 4), прирост составил 3-4 \%.

Функционирующие в рамках национальной инфраструктуры, контейнерные перевозки наиболее удобны для изучения логистических потоков, в связи с тем, что они распространены в мировом грузопотоке, однородны, универсальны и имеют собственный статистический слой информации.

Преимуществом контейнерных перевозок перед другими видами доставки является то, что их использование на больших расстояниях позволяет снизить совокупные издержки за счет следующих преимуществ:

- снижение рисков перемещения грузов за счет возможности комбинирования наземного и морского видов транспорта без перемены грузового места;

- унификация информационного сопровождения груза;

- адаптивность и эластичность систем поставок, возможность их быстрого восстановления после прерывания при преодолении барьеров входа; 
- унификация грузового места, первичной и вторичной упаковки.

Экономическая эффективность при контейнерной транспортировке в первую очередь достигается за счет технологических особенностей перегрузочной техники комбинированных контейнерных терминалов. Крупнотоннажные перегрузочные механизмы обеспечивают перегрузку контейнерной тары с одного вида транспорта на другой без выгрузки груза из контейнера, что позволяет товару находиться внутри одного грузового места в течение всего маршрута следования.

Так как сеть контейнерных терминалов является основой международной логистической сети контейнерных перевозок, внедрение новых и эффективное использование уже существующих терминалов станет одним из факторов, обеспечивающих развитие логистической инфраструктуры контейнерных перевозок на национальном уровне с целью интегрирования национальной сети в мировую логистическую систему контейнерных перевозок.

Основные пункты, обеспечивающие сферу деятельности контейнерной логистики, следующие:

- наличие существующей транспортной инфраструктуры;

- наличие существующей сети контейнерных терминалов;

- показатели грузового транзита;

- показатели потенциально возможного грузового транзита.

В результате проведенных исследований были выявлены основные контейнерные грузопотоки, проходящие по территории Беларуси. Данные потоки ограничены пятью направлениями, которые определяют границы логистической сети и имеют векторную направленность с определенной степенью насыщенности:

Поток № 1 направлен на такие страны, как Россия (кроме Северо-Западного и Северо-Кавказского федеральных округов, Крыма), Казахстан, Узбекистан, Киргизия, Туркменистан, Таджикистан.

С точки зрения входящих и исходящих контейнерных потоков, проходящих по территории Беларуси по данному направлению, он включает в себя потоки, сформированные между перечисленными государствами и Евросоюзом, а так же потоки, проходящие по суше из стран Юго-восточной Азии и Китая. В свою очередь, мощность потоков, имеющих влияние на Республику Беларусь, ограничена потенциалом инфраструктуры, расположенной на этих территориях, с преобладанием железнодорожного и автомобильного транспорта, а наполняемость - выбором субъектами логистической деятельности маршрута, проходящего по территории Беларуси.

Поток №2. В него включены страны балтийского региона (Литва, Латвия, Эстония, Северо-западный федеральный округ России, Финляндия);

Для данного направления характерно включение фидерных перевозок на части прохождения маршрута из основных европейских портов (фидерные перевозки - это довозка малыми судами до портов с фарватерами малой глубины), а так же перевозки по суше, которые обеспечивают доставку генеральных грузов внутрь континента (генеральные - контейнеро-пригодные грузы). Единый стандарт железнодорожных путей обеспечивает отсутствие технологического барьера при прохождении государственных границ.

Поток № 3 включает страны Каспийско-Черноморского региона (Украина, Армения, Грузия, Азербайджан, Южный федеральный округ России, Крым).

Третье направление включает в себя потоки из стран южной Европы и Турции по Черному морю и их распределение внутри материка железнодорожным, автомобильным и внутренним водным транспортом. А так же потоки из стран Европы в страны Каспийского бассейна.

Основные объемы контейнерных перевозок приходятся на страны Черноморского бассейна Россию и Украину.

Поток № 4 направлен на промышленный треугольник между Парижем, Берлином и Веной.

С позиции анализа состояния логистических потоков, проходящих через Республику Беларусь, данное направление является продолжением первого (Россия, Казахстан, Узбекистан, Киргизия, Туркменистан, Таджикистан). В совокупности они объединяют наземными потоками страны, входящие в Европейский промышленный треугольник, и страны, входящие в первое направление, а так же Юго-восточную Азию и Китай.

Промышленный Европейский центр включает в себя такие страны, как Австрия, Бельгия, Италия, Германия, Нидерланды, Франция, Чехия. С точки зрения анализа логистического потока, влияющего на Беларусь и направленного на эту часть Европы, в оценку входит Польша, расположенная между Беларусью и Европейским промышленным треугольником.

Поток № 5 направлен на основные трансконтинентальные европейские порты.

Европейские порты принимают основной объем грузов, следующих из Азии и Америки. Как и в случае с четвертым направлением, пятое является продолжением первого. Конечным пунктом доставки данных грузов становятся страны СНГ и Средней Азии

\section{ВЫВОДЫ}

На основании проведенных исследований выявлены следующие тенденции:

При условии формирования маршрута, проходящего по территории Беларуси, выбор субъекта логистической деятельности основывается не только на наиболее коротком расстоянии прохождения маршрута, но и на степени развитости логистической инфраструктуры для контейнерных перевозок, адаптивности институциональной и правовой среды Беларуси к условиям транзита грузов, следующих в контейнерной таре.

Благодаря тому, что контейнерные перевозки имеют дополнительные требования к созданию логистической инфраструктуры, основой логистической сети могут стать контейнерные терминалы, которые являются вершинами 
сети и наделяют ее свойствами, послужившими причиной создания контейнерных перевозок, как обособленного вида логистической деятельности.

Ввиду высокого удельного веса в мировом товарообороте контейнерные перевозки могут являться основой развития логистической среды Беларуси с точки зрения ее организационного развития на микро- и макроуровне.

\section{ЛИТЕРАТУРА}

1. Ивуть, Р. Б. Логистические системы на транспорте: учеб.-метод. пособие / Р.Б. Ивуть, Т.Р. Кисель, В.С. Холупов. - Минск: БНТУ, 2014. - 75 с.

2. Outlook on the Logistics \& Supply Chain Industry 2013 // Global Agenda Council on Logistics \& Supply Chain Systems 2012-2014 [Electronic resource]. — 2013. — Mode of ac-

cess:http://www3.weforum.org/docs/WEF_GAC_LogisticsSupplyChainSystems_Outlook_2013.pdf. — Date of access: 11.05.2014. - P. 8.

3. Logistics Performance Index // The World Bank Group [Electronic resource]. — 2014. — Mode of access: http://lpi.worldbank.org/sites/default/files/LPI_Report_2014.pdf. — Date of access: 24.08.2014.

4. Logistics Performance Index // The World Bank Group [Electronic resource]. - 2012. — Mode of access: http://siteresources.worldbank.org/TRADE/Resources/239070-1336654966193/LPI_2012_final.pdf. — Date of access: 24.08.2014.

5. Logistics Performance Index // The World Bank Group [Electronic resource]. — 2010. — Mode of access: http://siteresources.worldbank.org/INTTLF/Resources/LPI2010_for_web.pdf. — Date of access: 24.08.2014.

6. Logistics Performance Index // The World Bank Group [Electronic resource]. — 2007. _ Mode of access: http://siteresources.worldbank.org/INTTLF/Resources/lpireport.pdf. — Date of access: 24.08.2014.

7. Полещук, И.И. Страны СНГ, Литва, Латвия, Эстония, Грузия: сравнительный анализ уровня развития логистики / И.И. Полещук, Т.Г. Зорина, Т.В. Кузнецова, И.В. Кашникова, П.А. Лаврентьев // Совр. технологии управления. - 2014. - № 6 (42).— Режим доступа: http://sovman.ru.

8. Рынок международных контейнерных перевозок и их развитие // ПроВЭД: информационно-аналитическое издание [Электронный ресурс]. — М., 2013. — Режим доступа: http://timber.unece.org/ index.php?id=84. — Дата доступа: 08.05.2014.

9. Рынок международных контейнерных перевозок и их развитие // ПроВЭД: информационно-аналитическое издание [Электронный ресурс]. — М., 2013. — Режим доступа: http://timber.unece.org/ index.php?id=84. — Дата доступа: 08.05.2014.

10. Рынок международных контейнерных перевозок и их развитие // ПроВЭД: информационно-аналитическое издание [Электронный ресурс]. — М., 2013. — Режим доступа: http://timber.unece.org/ index.php?id=84. — Дата доступа: 08.05 .2014$.

Статья поступила в редакциюю 16 июня 2015 года. 